\title{
REVOLUCIÓN RUSA Y PRIMERA OLEADA MIGRATORIA (1917-1930)
}

\author{
The Russian Revolution and the First Wave \\ of Emigration (1917-1930) \\ Aliona PINTI ${ }^{1}$ \\ Universidad Pedagógica «Ion Creang» (Moldavia)
}

\section{Resumen}

La Revolución Rusa de octubre de 1917 fue uno de los acontecimientos más importantes del siglo Xx. Surgió la Rusia soviética que realizó importantes cambios políticos, económicos y sociales. Pero este nuevo régimen no se consolidó hasta su victoria en la guerra civil contra las fuerzas contrarrevolucionarias. Fue entonces cuando los rusos blancos derrotados en el conflicto y los descontentos con el régimen soviético comenzaron abandonar el país. Esta primera oleada migratoria entre 1917 y 1930 fue un precedente hasta entonces desconocido en la vida de Rusia. A través del estudio de la historiografía rusa —-soviética y emigrada—, así como del análisis de fuentes primarias, el presente trabajo aborda los acontecimientos producidos durante la Revolución Bolchevique, las causas de la emigración rusa y la vida de los emigrantes rusos en los países receptores, situados en Europa, Estados Unidos y Lejano Oriente.

Palabras clave: revolución bolchevique, Guerra Civil rusa, emigración, exilio, Unión Soviética

\section{Abstract}

The Russian Revolution from October 1917 was one of the most important events in $20^{\text {th }}$ century. The Soviet Republic implemented and made big social, political and economic changes. But this new regime couldn't established until the victory in the

1 Licenciada en Historia (Universitatea Pedagogică de Stat «Ion Creang», Chisinău) y máster en Investigación y Estudios Avanzados en Historia (Universidad de Zaragoza). Correo electrónico: aliona_p@hotmail.com Fecha de recepción del artículo: 8 de noviembre de 2017. Fecha de aceptación: 19 de enero de 2018. 
Civil War against the counterrevolutionary forces. It was then when the defeated in this conflict forces, white russians and discontented with the soviet regime began to leave the country. This first wave of emigration between 1917 and 1930 was absolutely new manifestation in the life of Russia. Having studied and analyzed the historiography of russian - soviet and from the part of emigrants, and the analysis of the primary sources, this work comprehends the events occurred during the Bolchevik Revolution, the reasons of the russian emigration and the life of the russian emigrants in the recipient countries, located in Europe, United States and Far East.

Key words: Russian Revolution, russian Civil War, emigration, exile, Soviet Union

\section{INTRODUCCIÓN}

El objetivo de este artículo es analizar la primera oleada migratoria (19171930) provocada por la Revolución Bolchevique de 1917 y la posterior Guerra Civil (1918-1923), que fraccionó el país en dos campos ideológicamente opuestos. Esta emigración estuvo compuesta por los militares, miembros de la Iglesia Ortodoxa e intelectuales, portadores estos últimos de la cultura rusa en el extranjero, lo que distingue este tipo de emigración de otras, motivadas por causas económicas.

Para realizar este estudio se han consultado las fuentes primarias y secundarias. En el catálogo digitalizado del Archivo General de la Federación Rusa se han consultado los documentos relacionados con la dinastía Románov: manifiestos, leyes promulgadas y correspondencia. También se han localizado documentos del gobierno bolchevique y del movimiento Blanco. ${ }^{2}$ Son también importantes los datos aportados por la revista Krasnii Arjiv (El Archivo Rojo) entre 1922 y 1941, fundada por el propio Archivo Central de la URSS. En ella se han publicado una gran cantidad de documentos sobre la historia de Rusia antes de 1917, sobre la Revolución Bolchevique, la Guerra Civil rusa y las relaciones internacionales de la URSS. ${ }^{3}$

De gran utilidad ha sido la página web oficial del historiador de la Universidad Estatal de Moscú, Vladimir Volkov, en la que se han publicado documentos, base de datos de los militares emigrados, monografías, memorias y fotografías referentes a la Guerra Civil Rusa y a la emigra-

2 Página oficial del Archivo General de la Federación Rusa: http://www.statearchive.ru [Consulta: 25 de julio de 2017].

3 http://www.crasniiarjiv.ru [Consulta: 12 de junio de 2017].

STVDIVM. Revista de Humanidades, 23 (2017) ISSN: 1137-8417, pp. 195-226 
ción blanca. ${ }^{4}$ También se han consultado revistas electrónicas: http:// www.historicus.ru, en la que se pueden encontrar publicaciones de los historiadores desde la Historia Antigua hasta la Contemporánea; http:// www.ciberleninca.ru, que contiene artículos históricos y tesis doctorales; http://www.rosspen.ru, revista creada con el propósito de estudiar la historia de los partidos desde finales del siglo XIX hasta mediados del siglo Xx; y http://www.dermoscop.weekly.ru, publicación que aporta información sobre la emigración rusa, así como datos demográficos. A las monografías de los historiadores rusos he accedido a través de las bibliotecas electrónicas: http://www.elibrary.ru y http://www.archipelag.ru.

Respecto a la metodología utilizada para la realización de este trabajo, se ha procedido, en primer lugar, a un detallado estudio de las fuentes secundarias que se han encontrado en las páginas web rusas. Este análisis bibliográfico se ha centrado en el trabajo de los artículos y monografías publicadas sobre la materia. Es un trabajo realizado principalmente por historiadores rusos, siendo un tema apenas trabajado por la historiografía española, más allá de algún buen estudio de síntesis. Esta bibliografía se ha traducido del ruso al castellano.

\section{UN ACERCAMIENTO HISTORIOGRÁFICO}

\subsection{Historiografía soviética y de la emigración (1917-1989)}

Desde los años veinte, los estudios sobre la emigración de la primera oleada no se pudieron realizar de manera objetiva. Todas las monografías publicadas por la historiografía soviética estuvieron impregnadas de ideología comunista y cualquier proceso histórico se limitó a la lucha de clases, realizándose estudios simplistas que distorsionaban la realidad. Otros obstáculos para el estudio de la emigración fueron tanto el aislamiento del país con respecto al resto del mundo, como el de los historiadores en particular y, sobre todo, la imposibilidad de acceder a los archivos soviéticos y extranjeros. ${ }^{5}$

En la primera mitad de los años treinta surgió, entre los historiadores soviéticos y los historiadores emigrados, el mismo afán por estudiar los

4 http://www.beloedelo.ru [Consulta: 12 de junio de 2017].

5 Valentina Ivanovna Zepilova, Istoricheskaia nauka Russkogo zarubezia 1920-1930, Ecaterinburgo, 2000: 2, http:// www.riku.ru [Consulta: 12 de junio de 2017]. 
recientes hechos acaecidos en Rusia. A partir de 1925, los historiadores rusos emigrados empezaron a publicar sus primeras obras, que entraban en contradicción ideológica con los historiadores soviéticos. Los historiadores emigrados se negaron a publicar sus artículos en las revistas de tendencia marxista dado que el gobierno bolchevique renovó el alfabeto cirílico mientras que los emigrantes mantenían el antiguo. Era una cuestión ortográfica, pero que limitaba la difusión de las obras de los emigrantes en las revistas publicadas en la Unión Soviética. Mijail Ivanovich Rostovtsev declaró públicamente que representar a Rusia en las conferencias internacionales podían hacerlo solo los intelectuales que vivían en el extranjero. Alexandr Borisovich Florovski y Andrei Alexandrovich Kizeveter afirmaron que la verdadera historia de Rusia se escribía por los emigrantes. Para los historiadores emigrados eran ellos quienes podían escribir con la libertad, mientras que los que residían en la Unión Soviética estaban presionados por el régimen. ${ }^{6}$

En este sentido, comenzó la «caza de brujas» contra los historiadores opuestos a la ideología comunista tanto dentro como fuera del país. En el otro extremo ideológico, en la URSS, entre los historiadores soviéticos, cabe destacar a Mijail Nikolaevich Pokrovski quien, desde 1918, dirigió la Academia Socialista, el Archivo Central, el Instituto de Profesorado Rojo, la revista Krasnii Arjiv (Archivo Rojo) y la Organización de Historiadores Marxistas. En una de sus obras, Istoricheskaia nauka y borba klasov (Historia como ciencia y la lucha de clase) afirmó que no se podía realizar ningún estudio sin una explicación marxista de los hechos. ${ }^{7}$

Entre los años 1917-1930 se establecieron, pues, las bases de la historiografía soviética de carácter marxista. Se caracterizaba por buscar una explicación a todos los grandes procesos históricos y por la utilización de un lenguaje muy específico. Se centraron en estudios sobre los procesos revolucionarios y la lucha de clases. La corriente marxista-leninista se ocupó exclusivamente del estudio de la historia del Partido y de la URSS. ${ }^{8}$ Los historiadores sovié-

6 Mijail Ivanovich Rostovzev (1879-1952), historiador ruso, reconocido como máxima autoridad mundial en la historia antigua de Rusia y Ucrania. En 1918 emigró a Estados Unidos y aceptó una cátedra en la Universidad Wisconsin-Madison y después en la Universidad de Yale en 1925. Alexandr Borisovich Florovski, (1875-1947), historiador ruso, después de su deportación en 1922, fue profesor en la Universidad Carolina en Praga, al igual que Andrei Alexandrovich Kizeveter (1866-1933), historiador reconocido ruso, también deportado en 1922.

7 Mijail Nicolaevich Pokrovski (1922), Istoricheskaia nanka y borba klasov, Moscú, ASD: 22, http://www.krasniiarjiv.ru [Consulta: 10 de junio de 1917].

8 Ivanovna, 2000: 20. 
ticos consideraron que la historiografía producida fuera de Rusia era la continuidad de la historiografía burguesa, que estaba en crisis. No obstante, durante un breve periodo, los historiadores soviéticos aún pudieron relacionarse con sus colegas en el extranjero, y las obras de los historiadores de ambas partes se publicaban tanto en la URSS como fuera de sus fronteras. ${ }^{9}$

Especial interés representa las obras del historiador emigrante ruso en Francia, Piotr Egorovich Kovalevski, quien realizó un estudio de Rusia desde la prehistoria hasta la formación de la Rus de Kiev (882 d. C.). ${ }^{10}$ Posteriormente, en 1971, Kovalevski publicó el libro Zarubeznaia Rossia (Rusia en el extranjero), ${ }^{11}$ donde estudió la emigración de la primera oleada. Allí ofreció datos biográficos y proporcionó información sobre la actividad científica, la creación de universidades, el estatus jurídico y las dificultades sufridas por los emigrantes. Estas dos monografías estaban libres de cualquier matiz ideológico al centrarse en los hechos históricos sin interpretarlos políticamente. En las décadas de los sesenta y setenta destacó la obra de Grigorii Borisovich Vernadski, ${ }^{12}$ Ocherki po istorii nankiv Rosii (Relatos sobre la historiografía en Rusia) donde estudiaba el conjunto de la historiografía rusa entre 1917 y 1945, tanto la procedente de la historiografía emigrante como la generada en la propia Unión Soviética.

Con la desestalinización, los historiadores de la Unión Soviética volvieron al estudio de la emigración de la primera oleada, pero sin poder todavía abordarla objetivamente. ${ }^{13}$ No fue hasta la Perestroika cuando se produjo cierta liberalización que dio paso a nuevos estudios sobre estas temáticas. Empezaron a publicarse estudios sobre las oleadas migratorias, la asimilación de los emigrantes, las instituciones, las publicaciones y las particularidades de la vida en los países receptores. Fueron obras escritas tanto por historiadores soviéticos como por historiadores que vivían fuera de la URSS. ${ }^{14}$

9 Mijail Borisovich Orlov, Oktiabrskaia revolinzia y istoricheskaia nanka, Moscú, MGU, 2013: 26, https://www.hse.ru, p. 26 [Consulta: de 11 de junio de 2017].

10 La obra de Piotr Egorovich Kovalevski, Istoricheskii puti Rossii: Sinteziz russkoi nanki, (El camino científico de Rusia: la sintesis), París, Paidós, 1949.

11 El libro Zarubeznaia Rossia se publicó también en París.

12 Historiador y profesor en la Universidad de Kiev, emigró en 1920 a Praga; fue profesor en la Universidad Carolina y en 1927 en la Universidad de Yale.

13 Anna Ignatievna Zvetcova, Otstuplenie na inge (Desplazamiento en el sur), Moscú, Svet, 1975; Andrei Gavrilovich Kovalenko, Kolchakovskaia opozizia (Oposición de Kolchak), Cheliabinsk, Zoria, 1980.

14 Valeria Ivanovna Fiodorova, Beloe dvizenie (Movimiento Blanco), Moscú, Luch, 1990: 35, http://www.archipelag.ru [Consulta: 4 de junio de 1917]. 


\subsection{Historiografía postsoviética (1989-2017)}

Tras la caída de la Unión Soviética, en la historiografía de la actual Federación Rusa se han producido cambios notables. Se abandonaron los estereotipos ideológicos, centrados en el mito de la Gran Revolución Socialista de Octubre, que habían dominado la historiografía soviética clásica. El acceso a nuevos datos y documentos permitió a los historiadores rusos realizar novedosos estudios sobre la emigración de la primera oleada migratoria (1917-1930). Se quería colmar el vacío de existente sobre el tema y recuperar el legado que habían dejado en el extranjero los grandes personajes, entre ellos, Iván Bunin, Alexander Kuprin, Konstantin Balmont, Dmitri Merezhovsky, Iván Shmeliov que formaban parte de esta emigración. En 1992, al año siguiente de la desaparición de la Unión Soviética, después de la revisión de las monografías editadas durante la época soviética y la publicación de las memorias de los emigrantes de la primera oleada vieron la luz una serie de obras importantes. Entre ellas destacó Beloe delo: otdelnie knigi (El asunto blanco: obras elegidas). Se trataba de un conjunto de textos dedicados al estudio del movimiento contrarrevolucionario, a las causas de la derrota y a la emigración de los militares. Hasta la actualidad se han publicado dieciséis volúmenes promovidos por el Centro histórico-cultural de Moscú. ${ }^{15}$ De gran importancia fue la digitalización de los documentos conservados en el Archivo Central de la Federación Rusa sobre la historia de la emigración blanca, bajo el título Russkaia voennaia emigrazia v 20-40 godaj Xx veka (La emigración militar rusa de los años 20-40 del siglo Xx). ${ }^{16}$ También se publicaron los documentos de Archivo de Praga referidos a la notable emigración rusa que se instaló en la por entonces República de Checoslovaquia. Una colección de relatos bajo el título Russkie bez otechestva (Rusos sin patria) fue publicada por los profesores de historia de la Universidad Estatal de Moscú. Estas colecciones abarcan todos los aspectos de la vida política, económica, social y cultural de todos los grupos sociales de la emigración rusa. ${ }^{17}$

15 Valeria Igorevna Goncharova; Igor Ivanovich Frolov; Andrei Fiodorovich Fiodorov; Ivan Valerievich Guschenko, Beloe delo: otdelnie knigi, Moscú, MGU, 1998. http:// www.beloedelo.ru [Consulta: 5 de junio de 2017].

16 Valerii Valerievich Bogdanov, Russkaia voennaia emigrazia v 20-40 godaj XX veka, Cheliabinsk, Zoria, 1999. http://www.archipelag.ru [Consulta: 8 de junio de 2017].

17 Fue publicada en revista Zurnalnii zal en 2001; se pude encontrar en http://www.magazines. russ.ru [Consulta: 8 de junio de 2017]. 
La emigración militar y las actividades de los militares en el extranjero fueron investigadas por Vladimir Volkov, historiador y profesor en la Universidad Estatal de Moscú. En Tragedia russkij ofizerov: ofizialnii corpus Rossii vo vremia revolinzii (La tragedia de los oficiales rusos: el cuerpo oficial de Rusia durante la revolución) describe la estructura, la composición social y la difícil situación en la que se encontraba el ejército ruso después de 1917, así como las motivos que llevaron a la creación del movimiento blanco por los oficiales rusos y la organización de los ejércitos antibolcheviques en el sur, el norte, el oriente de Rusia y en Polonia. En la monografía Russkoe voisko za granizei: epopeya Gallipoli (Ejército ruso en extranjero: la epopeya de Gallípoli) Vladimir Volkov relata los acontecimientos que vivieron los militares entre 1920 y 1923, especialmente la evacuación del ejército blanco a Constantinopla bajo el mando del general Wrangel, la vida de los militares en los campamentos en Gallípoli y el siguiente desplazamiento del ejército a Bulgaria y Yu-

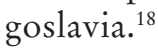

Vasiliy Ivanovich Goldin, profesor de la Universidad de Novgorod, en su monografía Voennii mir russkogo zarubezia: liudi y sudbi (El mundo militar en el extranjero: personas y destinos), a través del estudio de la documentación archivística, reconstruyó las biografías de los generales y los oficiales del ejército contrarrevolucionario en el extranjero..$^{19}$ Por su parte, la estructura del ejército zarista antes de la revolución, las causas del movimiento contrarrevolucionario y las organizaciones militares en el extranjero fueron estudiadas por el historiador Ivan Vasilievich Domnin en Tvorcheskaia misli $v$ izgnanii (El pensamiento militar en el exilio. ${ }^{20}$ Sergei Vladimirovich Karpenco, en su monografía Ocherqui istorii belogo dvizenia na inge Rosii, 1917-1920 (Relato bistórico sobre el movimiento blanco en el sur de Rusia, 1917-1920), realizó un estudio sobre las causas del movimiento militar contrarrevolucionario en el sur de Rusia durante la Guerra Civil. ${ }^{21}$ El movimiento contrarrevolucionario en Rusia entre 1917 y 1922 también fue estudiado por Vladimir Pavlovich Slobodin en Beloe

18 Vladimir Volkov, Russkoe voisko za granizei: epopea Galliopoli, Moscú, Universidad Estatal, 2003. http://www. beloedelo. ru [Consulta: 8 de junio de 2017].

19 Vasiliy Ivanovich Goldin, Voennii mir russkogo zarubezia: liudi y sudbi, Moscú, Luch, 2001. http://www.archipelag.ru [Consulta: 9 de junio de 2017].

20 Ivan Vasilievich Domnin, Tvorcheskaia misli v isgnanii, Moscú, Zoria, 2006. http:// www.elibrary.ru [Consulta: 9 de junio de 2017].

21 Sergei Vladimierovivh Karpenko, Ocherki istorii belogo dvizenia na inge Rosii (19171920), Rostov, Zoria, 2009. http://www.archipelag.ru [Consulta: 9 de junio de 2017]. 
dvizenie v godi grazdanskoi voini v Rosii (1917-1922) (El movimiento blanco durante la guerra civil 1917-1922). ${ }^{22}$

Las causas de la emigración militar, la actividad política, las fundaciones y la función de las escuelas y academias militares en el extranjero han sido investigadas por Anna Ivanovna Uriadova en su obra Velikaia voina $y$ russkaia emigrazia (La Gran Guerra y emigración rusa). ${ }^{23}$ La vida en el extranjero de los militares emigrados después de la Guerra Civil y el desarrollo de su vida política y cultural fue estudiada por Albina Kirilovna Skarenko en Belaia emigrazia (Emigración blanca). ${ }^{24}$ Sobre la actividad de los militares emigrados que pertenecían al ejército de Piotr Wrangel, quienes abandonaron Turquía y se instalaron en Francia, Konstantin Konstantinovich Semenov escribió Russkaia voennaia emigrazia vo Franzii v 1920-1945 (La emigración militar en Francia en los años 1920-1945). ${ }^{25}$

Alexei Fiodorovich Kiselev, en Politicheskaia historia russkoi emigrazii, 1920-1940 documenti y materiali (Historia politica de la emigración rusa, 1920-1940 documentos y memorias), publicó una serie de documentos que reflejan la actividad política del Comité Militar Ruso, fundado por Wrangel en Belgrado, en 1924, que reunió a los militares bajo un único mando. ${ }^{26}$

La historia general de los emigrantes rusos fue estudiada por Zinaida Semenovna Bocharova, profesora en la Universidad de Lomonosov de Moscú. En su obra Rossiiskoe zarubezie (1920-1930), kak fenomen otechestvennoy istori (El extranjero ruso (1920-1930), como fenómeno de la historia nacional) proporciona información sobre la vida de los emigrantes rusos en los países receptores, sobre sus organizaciones y sus actividades culturales y científicas durante la primera oleada migratoria. ${ }^{27}$ También sobre los emigrantes rusos de la primera oleada de 1917-1930 en países como

22 Vladimir Pavlovich Slobodin, Beloe dvizenie v Rossii (1917-1922), Arjangelsk, ARS, 2001. http://www.elibrary.ru [Consulta: 10 de junio de 2017].

23 Anna Ivanovna Uriadova, Velikaia voina y russkaia emigraziya, Moscú, SLK, 2005. http://www.elibrary.ru [Consulta: 9 de junio de 2017].

24 Albina Kirilovna Skarenko, Belaia Emigrazia, Moscú, Luch, 2003. http://www.elibrary. ru [Consulta: 9 de junio de 2017].

25 Konstantin Konstantinivich Semenov, Russakia voennaia emigraziavo Franzii v 19201945, Arjangelsk, ARS, 2010. http://www.elibrary.ru [Consulta:10 de junio de 2017].

26 Alexei Fiodorovich Kiselev, Politicheskia historia russkoi emigrazii, Minsk, SRL, 2011. http://www.archipelag.ru [Consulta: 10 de junio de 2017].

27 Zinaida Semionovna Bocharova, Rossiiskoe zarubezie (1920-1930), kak fenomen otechestvennoi istorii, Minsk,Svet, 2003. http://www.arhipelag.ru [Consulta: 11 de junio de 2017]. 
Alemania y Francia, escribió Valerii Viktorovich Kosticov Vizgnanii: puti y sudbi russkoi emigrazii (En el extranjero: caminos y destinos de la emigración rusa)..$^{28}$

El estudio sobre los emigrantes desde la revolución hasta el presente y sus problemas de asimilación fue realizado por Alexei Ivanovoch Pronin en Russkaia emigrazia kak obiect isledovania (Emigración rusa como objeto de estudio). ${ }^{29}$ La historiadora de la Universidad de Cheliabinsk, Evgenia Ivanovna Semochkina, en su obra Historia russkoi emigrazii. XX vek ( La bistoria de la emigración rusa. Siglo XX), estudió las causas de la emigración de la primera oleada de 1917-1930, la vida de los emigrantes y sus actividades culturales y científicas en los países receptores. ${ }^{30}$

El estudio de los emigrantes rusos de la primera oleada en Francia centra la obra de Katerina Guseva, Russkaia emigrazia vo Franzii: sozialinaia bistoria (Emigración rusa en Francia: historia social). Esta historiadora francesa, nieta de emigrantes rusos, aporta los documentos archivísticos y las memorias de los emigrantes, y realiza un estudio de la comunidad rusa que le permite reconstruir la situación de aquella época, a diferencia de otros historiadores que se centraron en el estudio de la vida de la elite. ${ }^{31}$ Vladimir Viktorovich Kovalev describió la vida cotidiana y la asimilación de los emigrantes rusos en Praga en su obra Povsednevnaia zizni rossiiskoi emigrazii v Prage v 1920-1930 (La vida cotidiana de los emigrantes rusos en Praga en los años 1920-1930). ${ }^{32}$ La historiadora de la Universidad de Voronez, Elena Igorovna Protasova, en Russkaia emigrazia v Chejoslovakii 1920-1930 (Emigración rusa en Checoslovaquia, 1920-1930), también estudió sobre los emigrantes rusos en la República de Checoslovaquia, su asimilación y las instituciones fundadas en Praga. ${ }^{33}$ La historiadora búlgara

28 Valerii Victorovich Kostikov, V izgnanii: puti y sudbi russkoi emigrazii, Moscú, Luch, 2005. http://www.elibrary.ru [Consulta: 11 de junio de 2017].

29 Alexei Ivanovich Pronin, Russkai aemigrazia kak obiekt issledovania, Moscú, Svet, 2009. http://www.archipelag.ru [Consulta: 11 de junio de 2017].

30 Evgenia Ivanovna Semochkina, Historia russkoi emigrazii. xx vek, San Petersburgo, Zoria, 2009. http://www.elibrary.ru [Consulta: 12 de junio de 2017].

31 Katerina Guseva, Russkaia emigrazia vo Franzii: sozialnaia historia: lindi y sudbi, Moscú, Luch, 2009. http://www.arhipelag.ru [Consulta: 12 de junio de 2017].

32 Vladimir Viktorovich Kovalev, Povsednevnaia zizni vo franzuskoi emigrazii y adaptazia 1917-1930, San Petersburgo, Zoria, 2003. http://www.elibrery.ru [Consulta: 12 de junio de 2017].

33 Elena Igorovna Protasova, Russkaia emigrazia v Checoslovakii 1920-1930, Arjangelsk, ARS, 2005. http://www.archipelag.ru [Consulta: 12 de junio de 2017]. 
Evgenia Solnzeva-Nakova, en Russkoe zarubezie y slavianskii mir (El extranjero ruso y el mundo eslavo), analiza las instituciones rusas en Bulgaria fundadas por los emigrantes rusos entre 1917-1940.34

La expulsión de los intelectuales de la URSS en 1922 se ha plasmado en diferentes investigaciones. Mijail Evgenich Glavaskii, en Filosofskii karabil 1922 (Barco filosófico: 1922), describe las causas y la trama urdida contra la inteligencia rusa y su siguiente expulsión al extranjero. Aporta los documentos que hasta hace poco tenían acceso restringido. ${ }^{35}$ Vladimir Genadievich Macarov y Valentin Sergeevich Cristoforov, en Pasaziri filosovskogo parajoda: sudiba ruskij emigrantov, vesna-osen 1922, (Los pasajeros del barco filosófico. El destino de los intelectuales rusos, verano-otoño 1922), describen la vida de los intelectuales en el extranjero y aportan datos biográficos sobre ellos. ${ }^{36}$ Andrei Borisovich Kvakin, en Reflexion o filosofskom parajode (Reflexión sobre el barco filosófico), describió las contradicciones que surgieron entre el nuevo gobierno y los intelectuales y la siguiente deportación de estos últimos. ${ }^{37}$

Pavel Alexeevich Tribunskiy, Sergei Vladimirovich Zuravlev y Lev Ivanovich Gusman, historiadores del Instituto de Historia en Moscú, en Russkoe nauchnoe zarubezie: liudi, trudi, instituzii, arjivi (Extranjero científico ruso: personas, obras, instituciones y archivos), aportaron información sobre la actividad de los científicos rusos en China, Alemania, Francia, Checoslovaquia y Estados Unidos. ${ }^{38} \mathrm{La}$ actividad científica de los intelectuales expulsados en 1922 en los países receptores fue estudiada también por Alexandra Ivanovna Vavilova en su monografía Rossiiskie uchenie $y$ inzineri $v$ emigrazii (Los científicos e ingenieros rusos en el extranjero). ${ }^{39}$

34 Evgenia Solnzeva-Nakova, Russkoe zarubezie y slavianskii mir, Moscú, SRL, 2011, http://www.elibrary.ru [Consulta: 12 de junio de 2017].

35 Mijail Evgenich Glavaskii, Filosofskii korabil 1922, San Petersburgo, Zoria, 2000. http:// www.archipelag.ru [Consulta: 13 de junio de 2017].

36 Vladimir Genadievich Macarov y Valentin Sergeevich Cristoforov, Pasaziri russkogo parajoda (sudbi russkoi emigrazii), Moscú, Luch, 2004. http://www.elibrary.ru [Consulta: 13 de junio de 2017].

37 Andrei Borisovich Kvakin, Reflexión o filosofskom parajode, Moscú, Svet, 2000. http:// www.archipelag.ru [Consulta: 13 de junio de 2017].

38 Pavel Alexeevich Tribunskiy, Sergei Vladimirovich Zuravlev, Lev Ivanovich Gusman, Russkoe nauchnoe zarubezie: liudi, trudi, instituzii, arjivi, Arjangelsk, Zoria, 2011. http://www.elibrary.ru [Consulta: 14 de junio de 2017].

39 Alexandra Ivanovna Vavilova, Rossiiskoe uchenie y inzineri v emigrazii, Moscú, Luch, 2006. http://www.archipelag.ru [Consulta: 14 de junio de 2017]. 
Por último, en relación con la Iglesia ortodoxa en el extranjero, Dmitrii Vladimirovich Jmirov, publicó Russkaia Pravoslavnaia Zercov za granizei (1920-1945) v otechestvennoi y zarubeznoi istoriografii (Iglesia rusa en el exilio (1920-1945), en las obras nacionales y en el extranjero). ${ }^{40}$ Por su parte, el investigador serbio Alexii Tarasiev describió la actividad religiosa de los clérigos rusos en Serbia emigrados después de la Revolución de Octubre en Russkie dujovnikiv Serbii, 1917-1940) (El clero ruso en Serbia entre 1917-1940). ${ }^{41}$

\section{EMIGRACIÓN DE LA PRIMERA OLEADA (1918-1930)}

El miércoles, 25 de octubre (7 de noviembre ${ }^{42}$ ) de 1917, el Gobierno provisional de Kérenski fue derrocado en Petrogrado. Los bolcheviques, apoyados en el Comité Militar Revolucionario del soviet de la ciudad, tomaron el poder: se ocuparon las oficinas de correos y telégrafos, las estaciones de tren y las guarniciones del ejército quedaban bajo su control. Su llegada al poder provocó la Guerra Civil Rusa (1918-1923). Durante cinco años se liberaron una serie de batallas entre el Ejército Rojo y el ex ejército zarista agrupado en el denominado Movimiento Blanco. El ejército contrarrevolucionario fue derrotado y la URSS se consolidó. Quienes se oponían a los bolcheviques tomaron el camino de exilio.

En Rusia, el fenómeno de la emigración no era muy usual, pero sí el de la inmigración. El gobierno ruso era reacio a que los ciudadanos abandonasen su país de origen. Así, hasta 1906, cualquier propaganda de emigración estaba penalizada por la ley, y el abandono del país ilimitadamente estaba prohibido. No fue hasta 1903, durante el reinado de Nicolás II (1894-1917), cuando los ciudadanos obtuvieron el derecho a poseer un pasaporte, derecho que hasta este momento había sido un privilegio de la nobleza. En las Ordenanzas de 1903 se regularizó la ley «Sobre los pasaportes, permisos internacionales y comunicaciones fronterizas», en las que se establecieron las normas de residencia fuera de Rusia: no más de cinco

40 Dmitrii Vladimirovich Jmirov, Russkaia Pravoslavnaia Zercov za granizei (19201945) v otechestvennoi y zarubeznoi istoriografii, San Petersburgo, Svet, 2011. http:// www.archipelag.ru [Consulta: 13 de junio de 2017].

41 Alexei Tarasiev, Russkie dujovniki v Servii (1917-19409, Moscú, Svet, 2000. http:// www.elibrary.ru [Consulta: 13 de junio de 2017].

42 El gobierno soviético de Lenin decretó el abandono del calendario juliano a favor del calendario gregoriano, que se utilizaba en prácticamente toda Europa. 
años para la nobleza y tres para el resto de los ciudadanos. Si el pasaporte no se renovaba cada seis meses o la persona no volvía por orden gubernamental, automáticamente se le retiraba la nacionalidad y, al retornar a $\mathrm{Ru}-$ sia, el individuo era enviado de por vida al exilio. No obstante, y pese a esta legislación, como el coste del pasaporte era exageradamente caro - quince mil rublos-, la mayoría de los ciudadanos rusos viajaban ilegalmente al extranjero a través de las fronteras del oeste de Rusia. En 1910, un 80 \% de quienes salieron del país emigraron sin pasaporte. ${ }^{43}$

Después de 1917, el proceso migratorio cambió. Los rusos ya no viajaban al extranjero con fines diversos, sino se exiliaban o eran expulsados del país por razones ideológicas. Los historiadores rusos establecieron una periodización a esta migración rusa después de 1917, dividiéndola en cuatro «oleadas» migratorias, que se diferenciaban entre sí por sus causas, sus orígenes geográficos, su duración y su intensidad.

Una primera oleada migratoria tuvo lugar entre la Revolución de 1917 y 1930. Durante este período emigraron tanto exmilitares como civiles y religiosos, y sus dos episodios más importantes fueron la Revolución y la finalización de la Guerra Civil. La cantidad de refugiados varía, según las fuentes, entre 2,5 y 5 millones de personas. ${ }^{44}$ Una segunda oleada de emigración tuvo lugar durante la Segunda Guerra Mundial (1941-1945). Finalizado el conflicto, se estima que los llamados «no retornados» se contaron entre las quinientas y las setecientas mil personas. ${ }^{45}$ Medio millón de personas salió del país durante la tercera oleada de emigración (1948-1990), durante la «Guerra Fría». Una cuarta oleada de emigración, iniciada a partir de 1990 y que persiste en la actualidad es una emigración que no tiene causas políticas, sino económicas, y que es difícil de precisar dado que dicha diáspora todavía no ha finalizado. ${ }^{46}$

\subsection{Emigración militar}

Entre 1917 y 1919 comenzó la emigración militar. Este éxodo, aunque se califica de emigración militar, no estuvo solo compuesta por militares pues

43 Bocharova, 2003: 16.

44 Piotr Pavlov, «Kto y kogda pokinul Rossiu v XX veke» («Emigración: quien y cuando abandono Rusia en el siglo XX»), Demoscop Weekly, 251 (2005): 60-67 [Consulta: 10 de mayo de 2017].

45 Bocharova, 2003: 16.

46 Pavlov, 2005: 67-90. 
estos fueron acompañados por sus familias y otros civiles que huían con ellos. Poco después, con la derrota de los ejércitos blancos, a partir de 1919, el proceso aumentó cuantitativamente. La salida se produjo por tres rutas: noreste, sur y extremo oriente. Las fronteras del norte estaban abiertas lo que permitió a los militares salir del país sin obstáculos. Los primeros países nórdicos que recibieron a los refugiados fueron Finlandia y Noruega, donde, en junio de 1920 se crearon los Comités de Refugiados, que funcionaron hasta 1921. Otra vía de escape fue la de oeste a través de los países Bálticos hacia Polonia, Checoslovaquia, Alemania y Francia. ${ }^{47}$

En el sur, después de la derrota de los ejércitos contrarrevolucionarios, se produjo la evacuación del Gobierno de Crimea y de los civiles adeptos al mismo. En enero de 1920, todos fueron evacuados desde los puertos de Novorosiisk y Odessa hacia Constantinopla. Se calcula el número total de estos refugiados en 25000 . Su lugar de destino fue el reino de los serbios, croatas y eslovenos, 8500; Bulgaria, 8600; Islas Príncipe, 13 000; Lemnos, 2000; Chipre, 1500; y Egipto, $4000 .{ }^{48}$

La evacuación de refugiados más numerosa se produjo a finales de noviembre de 1920 desde la península de Crimea. El gobierno de Francia se encargó del traslado de los militares derrotados y de los civiles que les apoyaban. Desde dicha península fueron evacuados alrededor de 110000 personas en 34 barcos. ${ }^{49}$ Posteriormente, el ejército fue dividido en tres cuerpos y distribuidos entre la península de Gallípoli y la isla de Lemnos. Los civiles se instalaron en campos de refugiados próximos a Constantinopla. A finales de 1923, el gobierno de Turquía propuso la nacionalidad turca a los emigrantes rusos, en su defecto, tenían que abandonar el país. ${ }^{50}$

En enero de 1921, la flota de Wrangel, unos 30 barcos, con alrededor de 5600 militares, fue evacuada hacia Constantinopla. Desde allí se trasladaron a Bizerta (Túnez), instalándose en la base militar francesa. Dada su precaria situación económica, muchos refugiados (alrededor de 3500) abandonaron la flota en búsqueda de trabajo en la colonia francesa. Por el alto coste de mantenimiento de los militares rusos y la negativa de otros países a compartir los gastos que generaban, el gobierno francés propuso varias opciones a los refugiados: ir a Brasil, volver a la URRS, alistarse en

47 Karpenco, 2009: 73.

48 Volkov, 2003: 123-127.

49 Slobodin, 2001: 45-61.

50 Volkov, 2004: 79-87. 
la Legión Extranjera francesa o buscar un medio de vida. Como estas opciones propuestas por el gobierno francés podían llevar a la desaparición del ejército blanco, para evitarlo, Wrangel organizó el traslado del contingente militar a Bulgaria. ${ }^{51}$

Después de la derrota de Alexander Kolchak en Siberia y la caída de la República del Lejano Oriente, desde Vladivostok, en octubre de 1922, alrededor de 6000 personas se trasladaron a Manchuria. La escuadra del almirante Gergei Stark evacuó 1800 militares y a sus familiares hacia el puerto Kenzan (Corea del Sur) y desde allí muchos se dirigieron hacia Shanghái. Como era una de las ciudades que entraba en el Tratado de Nankín ${ }^{52}$ no hacía falta visado para vivir allí. Una parte de los refugiados se trasladaron inmediatamente a Japón, Estados Unidos y Australia. ${ }^{53}$

\subsection{Expulsión de los intelectuales}

La expulsión de los intelectuales de la URRS por el gobierno soviético se produjo en 1922. Las causas fueron diversas: de carácter ideológico, la coyuntura de la Nueva Política Económica (NEP) y la actividad profesional de los intelectuales. Una de las principales razones fue el afán del gobierno soviético de establecer un control ideológico, pues la oposición de los intelectuales representaba un peligro para el nuevo régimen. En 1921, con la NEP, se permitió la apertura de pequeñas empresas privadas. De esta forma, se fundaron periódicos privados y, en 1922, en Moscú y en Petrogrado ya había alrededor de doscientos periódicos y revistas. En estas publicaciones aparecían muy a menudo críticas contra el nuevo gobierno realizadas por los filósofos y escritores rusos. ${ }^{54}$

Los principales opositores al gobierno soviético, los filósofos, reclamaban la libertad de expresión. Así, el más destacado, Nikolái Berdiáyev, escribió su Filosofía de la desigualdad (1918), un conjunto de acusaciones contra el bolchevismo, que se difundieron en numerosas conferencias. Berdiáyev fundó, en Moscú, la Academia libre de cultura espiritual y fue profesor durante un año en la Universidad de Moscú hasta su expulsión. Otros filósofos

51 Goldin, 2001: 55-59.

52 El Tratado de Nankin, firmado el 29 de agosto de 1842, fue un tratado de paz entre el Imperio Británico y la Dinastía china Qing, que marcó final de las Guerras del Opio.

53 Genadii Vasilievich Melijov, Russkaia emigrazia v kitae v 1917-1924 (Emigración rusa en China en 1917-1924), San Petersburgo, Zoria, 2006: 78-91.

54 Macarov y Cristoforov, 2004: 36. 
que formaron parte de la oposición al gobierno soviético fueron Nikolái Loski, que creó, en Petrogrado, la Asociación libre filosófica; y los sociólogos Petrim Sorokin y Nikolái Kareev, quienes fundaron en Moscú uno de los primeros centros de sociología. Todos ellos reunían a un gran público en sus charlas y conferencias donde criticaban el régimen soviético. ${ }^{55}$

Para eliminar la oposición de los intelectuales, el gobierno de Lenin tenía que establecer primero una acusación grave. Así, en el periódico bolchevique Pravda (Verdad), Lenin publicó varios artículos con acusaciones contra los intelectuales por sus actividades anticomunistas y por cooperar con organizaciones contrarrevolucionarias. Las denuncias estaban ideadas con el fin de crear una conciencia en la sociedad soviética de la existencia de un enemigo. En julio de 1922, fue constituida una Comisión para revisar todas publicaciones antisoviéticas escritas por los intelectuales. Todos aquellos que fueran declarados culpables tenían que ser expulsados del país. En agosto del mismo año se aprobó la deportación de los intelectuales por el Politburó. ${ }^{56}$

El tratado de amistad y cooperación de Rapallo (1922) entre la URRS y Alemania fue aprovechado por el gobierno soviético para dirigir una petición al ejecutivo alemán solicitando los visados para los intelectuales que iba a expulsar. El gobierno alemán dio permiso con la condición de que los visados fueron solicitados por los intelectuales personalmente y no por el gobierno soviético. ${ }^{57}$

En agosto de 1922, Pravda publicó una entrevista de León Trotsky concedida a una periodista americana en la que se explicaban las causas de esta deportación. Como los expulsados representaban un peligro potencial por ponerse de lado de los enemigos de Rusia Soviética en momentos tan críticos, tenían que ser fusilados, según las leyes de guerra. Por ello, y según Trotsky, la deportación de los intelectuales por el gobierno soviético tenía que ser vista como un acto misericordioso. Fueron expulsados 280 intelectuales y científicos. La salida forzosa se realizó en septiembre, desde Moscú y Petrogrado, en los barcos Oberburgomister Hacken y Prussia hacia Alemania y, un mes más tarde, desde Odessa hacia Constantinopla y Varna. ${ }^{58}$

55 Macarov y Cristoforov, 2004: 36.

56 Daria Zhukovskaia, «Prichini y sudbi russkoi emigrazii posle Revoliuzii 1917 goda», Historicus, 2004: 23, http://www.historicus.ru [Consultado: 12 de junio de 2017].

57 Macarov y Cristoforov, 2004: 92-103.

58 Tarasiev, 2000: 79. 


\subsection{Iglesia rusa ortodoxa en el extranjero}

A lo largo de la historia, el gobierno zarista había otorgado numerosos privilegios a la Iglesia Ortodoxa, que, a su vez, legitimaba el poder de los zares. Después de tomar el poder, los bolcheviques declararon la separación de la Iglesia y el Estado. Así, la Iglesia ortodoxa rusa se encontró sin apoyo oficial y, en uno de sus primeros decretos, emitido en enero de 1918, el nuevo gobierno bolchevique proclamó la libertad de conciencia y religión, y las organizaciones religiosas quedaron privadas del derecho de propiedad y de los derechos atribuibles a una persona jurídica.

Posicionada con el intento de retorno del régimen anterior, la Iglesia Ortodoxa rusa apoyó al Ejercito Blanco en la guerra civil. Este hecho fortaleció, aún más, la oposición bolchevique a la Iglesia Ortodoxa, que fue considerada una organización contrarrevolucionaria. La naciente Unión Soviética proclamó oficialmente la tolerancia religiosa pero, en la práctica, el gobierno desalentó la religión organizada y luchó por eliminar la influencia religiosa en la nueva sociedad soviética. ${ }^{59}$

En un principio, la Iglesia Ortodoxa siguió existiendo. Después de la Revolución de Febrero de 1917, se había establecido un sistema electoral para decidir las estructuras de la administración diocesana, y, el 19 de junio de 1917, tuvo lugar, en Moscú, el Congreso Diocesano de Clero y Laicos que, por votación secreta, eligió al arzobispo Tijon (Vasili Ivánivich Belavin) como arzobispo de la diócesis de Moscú y Kolmna. En agosto de ese mismo año se inauguró el Concilio Local de toda Rusia, que restableció el título de Patriarca en la Iglesia Ortodoxa rusa, que había sido derogado en 1721 por el emperador Pedro el Grande (1672-1725). ${ }^{60}$ Este concilio designó a Tijon como Patriarca de Moscú y toda Rusia. En septiembre de 1918, el trabajo del concilio se vio obligado a parar a causa de la Guerra Civil. Fue entonces cuando las relaciones entre la Iglesia y los bolcheviques empeoraron. El Patriarca realizó una serie de llamamientos al pueblo en los cuales criticaba al gobierno soviético y le acusaba de la catástrofe producida en país y de las crueldades cometidas en la persecución contra los contrarrevolucionarios. El Patriarca fue arrestado y, en mayo de 1922, llevado preso al Monasterio Donskói en Moscú. ${ }^{61}$

59 Slobodin, 2001: 105-110.

60 Entre 1721 y 1917, la Iglesia ortodoxa rusa fue administrada por el Santísimo Sínodo.

61 Jmirov, 2011: 55-60. 
En marzo de 1917, un grupo de clérigos de San Petersburgo formaron la Unión del Clero y Laicos Democráticos con un programa esencialmente socialista cristiano. Los acontecimientos de la Revolución de octubre condujeron a que esta parte del clero, alineada con las ideas más de izquierdas, insistiera en que la Iglesia tenía que adaptarse a las realidades del nuevo régimen bolchevique, revisar su actitud hacia la doctrina socialista y realizar cambios significativos en su tradición canónica y litúrgica, todo ello en contraposición a la postura que defendía el patriarca Tijon. Las autoridades soviéticas mostraron interés en este grupo de los llamados «renovacionistas», viendo en ellos la posibilidad de dividir y debilitar a la Iglesia Ortodoxa rusa. Esta cooperación entre el grupo de los «renovacionistas» y el régimen soviético condujo a un cisma directo de la iglesia patriarcal, en gran parte orquestado y apoyado por las autoridades bolcheviques. ${ }^{62}$

Sin embargo, el posicionamiento final de la Unión Soviética fue el de eliminar la religión, propósito que fue uno de sus objetivos ideológicos. Con este fin, el régimen bolchevique confiscó las propiedades de la Iglesia, ridiculizó a la religión, acosó a los creyentes y propagó el ateísmo en las escuelas. Muchos sacerdotes ortodoxos y creyentes fueron torturados, enviados a campos de trabajo u hospitales mentales o ejecutados. El gobierno soviético se hizo cargo de miles de iglesias y monasterios, o bien las destruyeron o convirtieron en edificios de uso secular. ${ }^{63}$

Ante esta situación, los obispos y los sacerdotes se sumaron a la emigración de esta primera oleada revolucionaria de 1917-1930. Desde el exilio, la Iglesia Ortodoxa jugó un papel importante en el apoyo espiritual y en proporcionar las iglesias donde congregarse los emigrantes rusos. Una de las primeras catedrales rusas ortodoxas fue la de Alejandro Nevski de París construida en 1861. Otra importante iglesia ortodoxa rusa fue levantada por los emigrantes rusos cerca de Paris, en Sainte- Geneviéve-desBois, en el cementerio ruso. ${ }^{64}$

Los sacerdotes ortodoxos en los países receptores se ocuparon del registro de los emigrantes rusos, anotando sus nacimientos, sus matrimonios y divorcios, y sus defunciones. Para poder formar a los futuros sacerdotes para la Iglesia Ortodoxa rusa, se fundó, en 1921, en la ciudad de Constantinopla, un seminario. Un año más tarde, se fundaban sendos seminarios

62 Ibidem.

63 Tarasiev, 2000: 79.

64 Ibidem. 
en Sofía y en París. Desde 1920 se construyeron iglesias y monasterios rusos en Francia, Alemania, Suiza, Bulgaria, Finlandia, Italia, Suecia, Harbin y Estados Unidos. ${ }^{65}$

\section{LOS EMIGRANTES RUSOS EN EL EXTRANJERO}

\subsection{Número, geografía y establecimiento}

Los primeros países que acogieron a los emigrantes fueron los países fronterizos y los países balcánicos. Checoslovaquia, Francia, Bélgica y Alemania los recibieron posteriormente. Por su parte, los gobiernos de Gran Bretaña, Italia y Suecia colaboraron económicamente, pero evitaron el establecimiento de los emigrantes en sus países. En noviembre de 1919, Estonia recibió alrededor de 40.000 militares y civiles; pero a finales de 1924, albergaba ya a solo 12.000 emigrantes rusos. El resto había partido hacia países occidentales. En Letonia, en 1921, se alojaban 120.000 emigrantes rusos; y, en 1935, eran ya alrededor de 233.400. Hasta marzo de 1920, Finlandia recibió alrededor de 20.000 emigrantes rusos, pero, a partir de esta fecha, la entrada fue restringida por las dificultades económicas del país finés. En 1922, la URRS y Finlandia firmaron un acuerdo para regular el retorno a su patria de los emigrantes rusos que lo desearan ${ }^{66}$.

Desde enero de 1918, Polonia fue uno de los principales destinos de los refugiados rusos. Así, a finales de 1920, contaba con 150.000 militares y civiles rusos, que se establecieron en campos de refugiados. Las condiciones de vida en Polonia fueron difíciles, puesto que el gobierno polaco les prohibió abandonar los campos de refugiados. En 1928, en Polonia aún vivía alrededor de 100.000 emigrantes rusos. Muchos abandonaron el país por la falta de ayudas económicas y se trasladaron a Estados Unidos o a Francia. ${ }^{67}$

En torno a 40.000 emigrantes rusos, procedentes de Constantinopla, Gallípoli y Lemnos, se trasladan al Reino de los Serbios, Croatas y Eslovenos. El rey Alejandro I (1922-1929) reconoció a los militares rusos sus graduaciones y se les permitió llevar sus uniformes. Dada esta situación favorable, Wrangel, junto con 120 oficiales, se instaló en la localidad serbia

65 Jmirov,2011: 67-82.

66 Pronin, 2009: 120-137.

67 Bocharova, 2003: 74. 
de Sremski Karlovciy y acantonó allí su cuartel general. Los emigrantes, tanto militares como civiles, fueron distribuidos entre las principales ciudades -Belgrado, Zemun, Sarajevo y Zagreb—, donde había más oportunidades de encontrar trabajo. Los emigrantes vivían en colonias-en 1924 había alrededor de 299-, y se fundó la Legación rusa en Belgrado. A partir de septiembre de 1922, los militares abandonaron el ejército en busca de trabajo. ${ }^{68}$

A Bulgaria se desplazaron 9.700 oficiales y 17.400 cosacos y soldados que vivían en los cuarteles. En este país, en 1922, se fundó La Unión de Retorno que favoreció que alrededor de 7.000 de oficiales y soldados volvieran a la URRS. La difícil situación económica de posguerra empeoraba la situación de los emigrantes. Alrededor de 14.500 refugiados rusos encontraron empleo, pero, a partir de 1925, el crecimiento de paro les obligó a trasladarse a Bélgica, Francia y Luxemburgo. ${ }^{69}$

Hasta 1924, Alemania fue uno de los países con el número más elevado de emigrantes rusos, debido a las relaciones diplomáticas entre Alemania y Rusia soviética, que permitieron la entrada y la salida legal de la población soviética, la facilidad de encontrar trabajo y el bajo coste de vida. Cabe recordar que este país fue el destino de los intelectuales expulsados en 1922. Entre 1919 y 1921, en Alemania vivían cerca de 300.000 emigrantes rusos y, entre 1922 y 1924, aproximadamente 500.000. Como en otros países, los emigrantes vivían en colonias en ciudades como Berlín, Múnich, Dresde y Baden-Baden. También, por causas económicas, a partir de 1924 la diáspora rusa se desplazó a Francia. ${ }^{70}$

El gobierno francés, más que cualquier otro, se implicó en el traslado de los militares y los civiles después de la derrota del ejército contrarrevolucionario en el sur de la URRS. El crecimiento de la diáspora rusa en Francia también se debía a que los intelectuales rusos hablaban el idioma francés, lo que facilitaba la búsqueda de trabajo. En París se establecieron organizaciones benéficas, diferentes uniones y organizaciones rusas. Además, con un menor crecimiento demográfico que los países vecinos, la mano de obra era necesaria en Francia después de las destrucciones materiales y de las pérdidas humanas de la Gran Guerra. A partir de 1923, las autoridades francesas facilitaron visados y, de esta forma, aumentó el nú-

68 Semochkina, 2009: 123-140.

69 Bocharova, 2003: 74.

70 Pronin, 2009: 140-148. 
mero de emigrantes rusos en el país, que encontraron trabajo en el campo y en la industria. ${ }^{71}$

En 1921, miles de refugiados fueron desplazados desde Turquía y los Países Bálticos a Checoslovaquia, haciéndose cargo el gobierno checoslovaco del coste del traslado. Praga fue uno de los centros culturales de los intelectuales rusos. Profesores rusos y ucranianos eran invitados a dar clase en las universidades del país. No obstante, en 1928 el gobierno promulgó una ley que limitaba la contratación de mano de obra extranjera para quienes se instalaron en el país después de 1 de mayo de 1923. Su objetivo era proteger su mercado laboral. En aquel momento, se creó una comisión para el traslado de emigrantes a países como Francia, Bélgica, Holanda, Argentina y Canadá. ${ }^{72}$

Respecto al frente más oriental de la guerra civil rusa, después de la derrota de los ejércitos contrarrevolucionarios en el extremo sureste de la URRS, unos 15000 militares y civiles se desplazaron a China y 20000 a Corea. La situación de los emigrantes en China, a quienes se les permitió instalarse en la zona del norte, fue más que difícil por la falta de recursos económicos. Las autoridades chinas confiscaron toda la munición militar a los emigrantes militares rusos. Las ciudades donde se estableció un mayor número de emigrantes fueron Shanghái y Harbin. En ellas, que hasta 1917 habían sido áreas de negocios para los comerciantes y banqueros rusos, existía una comunidad rusa constituida por personas que trabajaban en las estaciones ferroviarias. Así, los emigrantes rusos encontraron el apoyo de quienes ya vivían allí. ${ }^{73}$

En Belgrado, en 1924, y en Praga y Berlín, un año más tarde, fueron fundadas asociaciones de colonización rusa, con el propósito de trasladar a los emigrantes rusos a América Latina. El país que recibió el mayor número de emigrantes rusos fue Argentina, seguida de Brasil, Paraguay y Uruguay. En 1925, el gobierno de Canadá permitió la entrada a 5000 emigrantes rusos que se encontraban en Manchuria, pero con la condición de ejercer la profesión de agricultor. Los Estados Unidos permitieron la entrada de emigrantes rusos en febrero de 1920. Su traslado fue realizado por

71 Ibídem.

72 Guseva, 2009: 56-72.

73 Nadezda Andreevna Egorova, Russkia emigrazi v Kitae (Emigración rusa en China), Cheliabinsk, SVT, 2005: 35-61. http://www.elibrary.es, [Consultado: 14 de junio de 2017]. 
el propio gobierno estadounidense y la Cruz Roja. De ellos, un $45 \%$ procedía de Turquía, un $35 \%$ del Lejano Oriente y el $20 \%$ restante llegaron por su cuenta a los Estados Unidos. Así, en 1925 en este país vivían unos 2248 emigrantes rusos. $^{74}$

Otro importante núcleo de emigrantes rusos procedió del cuerpo diplomático, que tras la revolución bolchevique se quedó en los países donde ejercían su función. Antes de 1917, el gobierno ruso mantenía relaciones diplomáticas con nueve países - Alemania, Estados Unidos, Austria, Gran Bretaña, Francia, Turquía, España, Italia y Japón-, con sus respectivas embajadas. Después de la Revolución bolchevique, el gobierno soviético pidió la colaboración a los diplomáticos rusos, antes al servicio del zar, para representar los intereses de la URRS en los distintos países, pero no recibió respuesta. Veintiocho exempleados de las embajadas zaristas siguieron funcionando y representando los intereses de la Rusia zarista, puesto que las embajadas tenían a su disposición fondos financieros. Así, en febrero de 1921, en París, se formó el Consejo de los embajadores, una institución sin carácter oficial, pero que representaba a la Rusia de Nicolás II (1868-1918). Este consejo llegó a contar con un representante en la Sociedad de las Naciones, cuya función fue la de defender los derechos de los emigrantes rusos. ${ }^{75}$

En esta dirección, y para consolidar un gobierno ruso en el exilio, en noviembre de 1920, durante una de las reuniones de los militares en Constantinopla, se eligió a Piotr Wrangel como representante y jefe del gobierno ruso en el extranjero. En abril de 1921, se creó el Consejo Ruso como un organismo gubernamental, pero un año más tarde se cerró por las luchas políticas internas. Wrangel y otros militares, para poder preservar el poder militar en los países receptores, fundaron la Unión Militar RusaROVS en 1924. Esta organización reunía a todos los militares rusos bajo un solo mando fuera de su patria. ${ }^{76}$

Cabe destacar la colaboración de la Cruz Roja rusa —fundada en 1879 y disuelta por el gobierno soviético en 1918- en la ayuda a los emigrantes, aunque esta institución seguía funcionando en el extranjero gracias a las donaciones benéficas de distintas organizaciones civiles, religiosas y de la Sociedad de las Naciones. También fueron fundadas las Uniones de

74 Pronin, 2009: 155-160.

75 Kiselev, 2011: 55-67.

76 Uriadova, 2005: 35-41. 
Zemstvo, que se ocuparon de proporcionar ayudas financieras, realizar búsquedas de empleo y promover ayudas médicas y jurídicas para los emigrantes rusos. ${ }^{77}$

Las colonias, las instituciones fundadas, las universidades, las escuelas y academias rusas crearon las condiciones necesarias para que los emigrantes rusos mantuvieran su propia idiosincrasia, permaneciendo, en gran medida, aislados de las sociedades de los países que los habían acogido. Así, en París, los miembros de la comunidad rusa seguían hablando el idioma ruso, compraban en las tiendas rusas, leían periódicos en ruso y los niños iban a escuelas rusas. Este estilo de vida de vida aislado perduró hasta 1930, cuando se esfumó la esperanza de volver a su patria. Entonces las instituciones se cerraron y comenzó el proceso de asimilación.

\subsection{Regularización de los emigrantes y pasaportes Nansen}

Con la primera oleada migratoria (1917-1939) surgió, en los países receptores, el problema de qué hacer con el elevado número de refugiados rusos. Por una parte, el nuevo gobierno soviético no tenía, por entonces, representación en ningún país y, por otra parte, la Rusia zarista se fue desvaneciendo y los emigrantes perdieron la ciudadanía rusa. En junio de 1921, en una de las sesiones de la Sociedad de las Naciones, se nombró a Fridjof Nansen ${ }^{78}$ como comisario de asuntos para los refugiados rusos. Los problemas a resolver eran muchos, tales como la distribución geográfica, la búsqueda de empleo o la regularización documental. Todo ello conllevaba un coste enorme para los países receptores. ${ }^{79}$

En agosto de 1921, la Comisión Jurídica de la Sociedad de las Naciones comenzó el trámite de la regularización de los refugiados. En julio de 1922, se celebró en Ginebra la conferencia entre los países con el mismo problema, donde se aprobaron los llamados pasaportes Nansen. Para recibir este pasaporte el refugiado tenía que cumplir varios requisitos: pagar la tasa correspondiente, estar registrado como refugiado y tener documento de identificación personal, expedido por la administración de la época zarista, por el Gobierno Provisional o por la URSS. Estos pasaportes fueron recibidos por los refugiados en sus lugares de residencia, en el idioma del país

77 Kiselev, 2011: 72-80.

78 También fue el comisario del programa de ayuda para los millones de personas que morían en la hambruna rusa de 1921.

79 Pronin, 2009: 165-170. 
de acogida y traducidos al francés. En marzo de 1924 los pasaportes Nansen ya eran reconocidos por treinta países. ${ }^{80}$

A partir de septiembre de 1928, en una de las sesiones de la Sociedad de las Naciones se rectificaron varias cláusulas: los pasaportes pasaron a tener validez de un año; se permitía no solo la salida del país, sino también el regreso (hasta 1928 se autorizaba solo la salida del país); el coste del pasaporte tenía que ser el más bajo posible y quienes no tenían recursos lo recibían gratuitamente; y, en el caso de la expulsión de cualquier país, no se les confiscaban sus documentos. ${ }^{81}$

En cada país receptor se tomaron medidas referentes a los emigrantes, según su legislación. Turquía fue el país que recibió el primer empuje de la oleada migratoria rusa, debido a que, como hasta 1923 Turquía estuvo ocupada por las tropas de los Aliados, los emigrantes rusos no estaban bajo jurisdicción turca. En 1924, el gobierno de Turquía ofreció asilo político a los emigrantes rusos, pero a partir de 1925, para proteger el mercado laboral, el gobierno prohibió la contratación de extranjeros en el país. ${ }^{82}$

Polonia fue también uno de los países que recibió gran cantidad de refugiados, pero, después de la firma de paz de Riga ${ }^{83}$ (marzo, 1921), el gobierno polaco les prohibió la formación de cualquier institución no autorizada por el gobierno soviético. Los emigrantes rusos que habían entrado en el país antes de septiembre de 1919 recibieron cartas de asilo político. A partir de 1924 comenzaron a expedirse residencias permanentes y se permitió el desplazamiento por todo el país. En 1928 Polonia reconoció los pasaportes Nansen. ${ }^{84}$

En Alemania se permitió la entrada al país solo a aquellos que tenían visado de salida. Aun así, el gobierno alemán tenía que enfrentarse al problema del destino de la gran cantidad de emigrantes rusos que se encontraban en el país. A partir de junio de 1921 a todos los que no podían recibir el pasaporte soviético se les expidieron pasaportes temporales alemanes. En 1922 se creó la comisión que se ocupó de lo referente a los refugiados rusos. Después del Tratado de Rapallo (octubre, 1922), el gobierno alemán dejó de reconocer los pasaportes que no habían sido expedidos por el gobierno soviético. ${ }^{85}$

80 Seminovna 2003: 91.

81 Ibidem.

82 Pronin, 2009: 175-180.

83 Firmada entre Polonia y la URSS se dio el término de la guerra polaco-soviética.

84 Kiselev, 2011: 83-91.

85 Ibidem. 
Francia, el país que más se implicó en la evacuación y ayuda a los emigrantes rusos, fue el primero en firmar la Convención de la Sociedad de las Naciones de 1928. La regularización de los emigrantes rusos se realizó sin ningún impedimento, lo cual permitió a los rusos su libre desplazamiento por todo el país, el acceso a los puestos de trabajo y recibir atención médica. Los pasaportes Nansen se expendieron solo a quienes abandonaron el país antes del reconocimiento de la URSS por parte del gobierno francés en octubre de 1924. A partir de 1927, los emigrantes que llevaban residiendo en Francia más de tres años y quienes terminaban sus estudios en universidades del país obtenían el derecho a solicitar la nacionalidad francesa. En el caso de matrimonio entre un ruso y un ciudadano francés, se podía solicitar la nacionalidad después de un año de matrimonio y los hijos de esta unión la obtenían sin ningún impedimento. ${ }^{86}$

En el Reino de Serbios, Croatas y Eslovenos los refugiados rusos que no reconocieron el gobierno soviético recibieron un estatus diferente a los demás extranjeros. A través de las instituciones que se ocupaban de los asuntos de los refugiados rusos se regularizó la situación legal de los emigrantes y se expidieron los pasaportes Nansen. Los emigrantes rusos que participaron en la Primera Guerra Mundial, los exmilitares del ejército ruso y los funcionarios tenían derecho a una pensión. Después de cinco años de residencia obtenían la posibilidad de solicitar la nacionalidad en el país. ${ }^{87}$

Hasta 1923, Bulgaria fue uno de los países con mejores condiciones para los emigrantes rusos. Se les permitió la fundación de instituciones y escuelas rusas, y, junto con los pasaportes Nansen, se les expidieron pasaportes búlgaros que regularizaron su situación. A partir de 1924, el gobierno búlgaro empezó a pagar las pensiones a los exmilitares rusos que habían participado en la guerra ruso-turca de 1877-1878. A partir de 1927 se abanaron ayudas sociales a todos los emigrantes rusos. Se facilitaron los requisitos para recibir la nacionalidad para quienes habían entrado en el país antes de 1929: se abarató el coste de los trámites y la duración de la residencia previa se acortó a los tres años, en vez de los diez establecidos hasta el momento. A todo ello se sumaba que, al ser un país de idioma eslavo, la asimilación se realizó con más facilidad. ${ }^{88}$

86 Semenov, 2010: 72-75.

87 Bocharova, 2003: 103.

88 Pronin, 2009: 183-184. 


\subsection{Partidos políticos y desarrollo científico y cultural}

Una vez en el extranjero, los oficiales del Ejército Blanco comenzaron a formar instituciones monárquicas con el propósito de seguir luchando contra los bolcheviques y restaurar la monarquía de los Románov en Rusia según las leyes del Imperio Ruso. En 1921, en Reijenga (Baviera), se convocó el Congreso de recuperación económica de Rusia. En este congreso se decidió formar el Consejo superior monárquico, con el dirigente Nicolai Marcov y como candidato al trono de Rusia el primo de Nicolás II, el gran duque Kiril Vladimirovich Romanov. Por su parte, en 1921, los kadetes, con el dirigente Pável Miliukov, decidieron crear diversos comités con representantes en Berlín, París, Sofía y Praga. Miliukov elaboró una nueva estrategia: el abandono de la lucha armada contra los bolcheviques y restablecimiento futuro de un gobierno republicano en Rusia. ${ }^{89}$

El ya citado Yiuli Martov, después de abandonar la URSS en 1921, se instaló en Berlín, que se convirtió en el centro del partido Social Democrático de los mencheviques. Se fundó la revista Sozialisticheskii vesnik (El Mensajero Socialista) desde la cual se criticó severamente el régimen bolchevique. Los miembros del Partido Social-Revolucionario, con su dirigente Vladimir Chernov al frente, convocaron en 1923, en la ciudad de Praga, un congreso para fijar el futuro de su partido, pero pronto surgieron discrepancias internas que llevaron a su disolución. En 1924, Iurii Arnoldi fundó la Unión Democrático-Republicana, con el objetivo de reunir a los emigrantes rusos de tendencia no monárquica. No obstante, los partidos políticos rusos, o lo que había quedado de ellos en los países receptores, no tuvieron éxito entre los emigrantes rusos porque estos los consideraban culpables de lo que había acontecido en la Rusia zarista y en los meses siguientes a su caída. ${ }^{90}$

Los científicos, una vez en el extranjero, fundaron diferentes instituciones para estar unidos y seguir colaborando. Las ciudades con más actividad científica fueron Berlín, Praga, París, Belgrado y Sofía. En octubre de 1921, se formó en Praga la Academia Rusa de las Ciencias, que agrupó a científicos rusos. En 1923, en la misma ciudad, se fundó la Asociación de los historiadores rusos. Los objetivos de estos historiadores de la vieja escuela en el extranjero fueron el desarrollo profesional y la posibilidad de

89 Kiselev, 2011: 103-114.

90 Ibidem. 
comunicarse entre ellos. Entre 1923 y 1938 se celebraron ocho congresos de historiadores rusos en la emigración. ${ }^{91}$

En abril de 1925, después del fallecimiento del historiador y arqueólogo ruso Nikodim Kondakov, se publicó su última obra, Russkaia Ikona ${ }^{92}$ (El icono ruso), cuyas ganancias se destinaron a ayudar a los intelectuales rusos en su desarrollo científico y literario. Con el mecenazgo de Nadesda Abricosova, esposa del presidente de Checoslovaquia, Tomas Masaryk, quien pertenecía a una familia aristócrata de Moscú, se fundó la Institución de investigación que recibió el nombre de Nikodim Kondakov. Hasta finales de la Segunda Guerra Mundial, dicha institución se ocupó del estudio del arte antiguo ruso, bizantino y oriental. Disponía de su propio archivo y biblioteca y también de una importante colección de iconos rusos y de telas coptas. Entre 1925 y 1938 la institución publicó nueve colecciones con el título de Seminarium Kondakovianum, que contenían artículos sobre arqueología e historia antigua rusa y diversos libros dedicados a los iconos rusos. ${ }^{93}$

En Belgrado se publicó la revista Sbornik Russkogo argeologicheskogo obschestva (Colección de la asociación arqueológica rusa, 1917-1940); y, en Berlín, Istorik y sovremennost (Historiador y actualidad, 1922-1924). En 1924, el historiador ruso Evgeniy Shzmurlo, de la Universidad Carolina en Praga, fundó Vvedenie v russkuiu historiyu (Introducción a la historia rusa). Estas revistas eran el resultado del creciente interés por la historia de Rusia, que también se tradujo en la publicación de monografías sobre el tema por parte de historiadores rusos, pero en el idioma de cada país. Los historiadores rusos siguieron trabajando en el extranjero, a pesar de la imposibilidad de utilizar los archivos y las bibliotecas en la URSS. ${ }^{94}$

En 1920, en Belgrado, se abrió una biblioteca pública rusa en el edificio de la Academia de las Artes y de las Ciencias de Serbia. En Praga, el gobierno financió la apertura de archivos y museos. En febrero de 1923 se abrió el Archivo Histórico Ruso, con el propósito de almacenar y registrar la documentación sobre la historia de Rusia que fue dirigido por historia-

91 Kostikov, 2005: 25-30.

92 Esta obra publicada en cuatro tomos analiza la evolución de los conceptos temáticos de los pintores desde el periodo bizantino, a través del principado de Kiev, hasta la culminación en el imperio ruso.

93 Andrey Ivanivich Anisimov, Bozia Mater, (Virgen María), Marina Nikolaevna Teniseva, Emal y inkrustazia, (Esmalte y incrustación).

94 Kostikov, 2005: 28-35. 
dores rusos como Alexander Alexandrovich Kizeveter, Peter Struve, Eugenio Franczevich Shmurlo y Venedikt Alexandrovich Miakotin..$^{95}$ El Archivo Histórico Ruso almacenó una gran colección de documentos sobre la vida política y social de los emigrantes rusos, revistas y periódicos entre 1918 y 1945 y una gran cantidad de documentos relacionados con la Revolución Bolchevique y la Guerra Civil rusa. En 1935, por iniciativa de Valentin Bulgákov, ${ }^{96}$ en Praga, se abrió el Museo de Historia Rusa. ${ }^{97}$

Respecto a la vida de los emigrantes rusos, su afán por conservar su identidad se manifestó en la apertura de guarderías, colegios y universidades rusas. Los estudiantes pudieron, en muchas ocasiones, convalidar los estudios realizados en Rusia y, así, continuarlos en los países de acogida y licenciarse. Ya durante la guerra civil, las embajadas rusas crearon comisiones para facilitar la continuación de los estudios de los emigrantes en los países donde fuera necesario. Estas comisiones funcionaban en las propias embajadas donde se examinaban quienes deseaban estudiar en universidades extranjeras. Junto a estas comisiones, las academias rusas de las Ciencias en Checoslovaquia, Francia y la República China desempeñaron el mismo papel para examinar a los futuros estudiantes. ${ }^{98}$

Praga fue la ciudad que más profesores emigrantes rusos agrupó. Estos fundaron en la capital checoslovaca la Unión del profesorado ruso (1922-1935), entidad que se creó con el objetivo de reunir a todos los profesores y ayudar a este colectivo en la búsqueda de empleo. Uniones similares se crearon en Bulgaria, Francia, Alemania, Finlandia y Yugoslavia. Se abrieron universidades rusas en Praga, París y Harbin (China). En el caso de la universidad rusa de Praga, el gobierno checoslovaco no sólo apoyó la apertura de la Universidad, sino que la financió. Ello ha llevado a calificar a la capital checoslovaca como el «Oxford» ruso. En 1930 se fundó la Unión rusa de universitarios para ayudar a buscar trabajo a los licenciados. ${ }^{99}$

De gran importancia en la transmisión de la cultura rusa fueron los escritores rusos en el extranjero. Al principio, el centro literario era Berlín.

95 P. Srtuve (1870-1944), fue historiador y cadete que emigró en 1921; E. F. Shmurlo (18531934) fue historiador y profesor en la Universidad de San Petersburgo y emigró en 1921; V. A. Miakotin (1867-1937) fue historiador y escritor, deportado en 1922.

96 Valentin Bulgákov fue el secretario de León Tolstói.

97 Tribunskiy, Zuravlev y Gusman, 2011: 45.

98 Protasova, 2005: 67-89.

99 Ibidem. 
En 1922, en esta ciudad se fundó la Casa de Arte y un año más tarde se abrió el Club de Escritores rusos. En 1926, los escritores se desplazaron a París donde abrieron otro club con el mismo nombre que reunió a literatos como Iván Bunin, Alexander Kuprin, Konstantin Balmont, Dmitri Merezhovsky e Iván Shmeliov. Entre los más exitosos se encontraban Alexander Kuprin e Iván Bunin, cuyas obras han sido traducidas a más de dieciocho idiomas. ${ }^{100}$

Dos años más tarde, en 1928, se celebró en Belgrado el primer Congreso de escritores y periodistas rusos en el extranjero. En este congreso se acordó la fundación de la Unión de escritores y periodistas rusos en el extranjero. Esta agrupó a 600 miembros y se decidió convocar cada año un nuevo encuentro en París. Los objetivos de esta unión iban dirigidos a conservar el legado literario ruso para transmitirlo a futuras generaciones. De gran importancia simbólica fue la decisión de celebrar anualmente, en todos los países donde se asentó la diáspora rusa, el día de la Cultura rusa. Para esta celebración se eligió el 8 de junio, día en que había nacido Alexander Pushkin. ${ }^{101}$ No en vano, los integrantes de esta primera oleada migratoria se consideraban a sí mismos como portadores y transmisores de la cultura rusa anterior a la Revolución bolchevique. Un importante transmisor de esta cultura fue el ballet ruso. En 1906, el empresario ruso Serguéi Diáguilev fundó la empresa Ballets Rusos, con los mejores integrantes del Ballet Imperial del Teatro Mariinski de San Petersburgo, dirigidos por el gran coreógrafo Marius Petipa. Tras la Revolución bolchevique, la empresa de Diáguilev y los artistas que la componían pasaron a formar parte de los emigrantes de la primera oleada. ${ }^{102}$

\section{Conclusiones}

La Revolución Bolchevique de 1917 fue uno de los acontecimientos más importantes del siglo XX. La perspectiva que ofrece el paso de cien años permite examinar la evolución historiográfica: por una parte, las investigaciones de los historiadores soviéticos, impregnados por la ideología marxista imperante en la Unión Soviética, que se ocuparon exclusivamente del estudio de la historia del Partido y de la URSS, incluso durante la época de desestalinización; por otra, las investigaciones y los trabajos de los histo-

100 Bocharova, 2003: 270.

101 Ibidem.

102 Ibidem. 
riadores rusos emigrados de la «vieja escuela» o los expulsados de la Rusia soviética por criticar el nuevo régimen bolchevique. Estos últimos fueron sustituidos, posteriormente, por los hijos y nietos de la emigración. Todas estas generaciones de historiadores procedentes de la emigración contaban con dos ventajas importantes: conocer el idioma ruso y la historia de la emigración rusa, por ser su propia experiencia vital. El inconveniente de esta historiografía era precisamente que esta vinculación ponía en duda su objetividad.

Solo con la disolución de la Unión Soviética en 1991, y gracias a la posibilidad de acceder a los archivos, hasta ese momento férreamente censurados, se produjo un importante giro historiográfico que, como aseguran los actuales investigadores de la Federación Rusa, ha permitido realizar un estudio más profundo y objetivo. Profundo por el acceso a fuentes primarias y objetivo por ser realizado por historiadores ya no tan directamente vinculados con el objeto de estudio, como lo eran los historiadores soviéticos y los de la emigración.

Los emigrantes que abandonaron Rusia a partir de 1917 representaban a todos los estratos de la sociedad, desde los familiares del zar, hasta campesinos y cosacos. La emigración de la primera oleada estaba formada por militares, intelectuales y religiosos.

Los militares emigrados desarrollaron actividades que, al principio, les permitió estar unidos con el propósito de conservar el Ejército Blanco. Tenían la esperanza de volver a su patria y restablecer el régimen zarista. Los políticos desempeñaron su actividad en el extranjero, pero, estos partidos políticos no tuvieron éxito entre los emigrantes rusos, porque fueron vistos como responsables de lo que había sucedido en la Rusia de Nicolás II.

Los intelectuales parecían tener mucho más claro que no había marcha atrás, y prosiguieron su vida científica y cultural allí donde se instalaron, creando sus propias instituciones. El objetivo de los historiadores de la «vieja escuela» fue seguir trabajando y comunicarse entre ellos. Los historiadores rusos fundaron revistas y publicaron obras sobre historia de $\mathrm{Ru}-$ sia a pesar de la imposibilidad de acceder a los archivos y bibliotecas en la Unión Soviética.

Los emigrantes rusos se esforzaron por conservar su identidad. Se abrieron guarderías, colegios, academias militares, seminarios y se construyeron iglesias ortodoxas rusas. Los estudiantes pudieron seguir estudiando y quienes tenían estudios en la Rusia zarista pudieron tramitar la convalidación de sus estudios en los países receptores. 
En conclusión, esta primera emigración fue, como fenómeno histórico, única en Rusia, tanto por sus motivaciones como por el elevado número de afectados. No sólo se exiliaron alrededor de 4, 5 millones de personas sino que, por su estrato social, quienes lo hicieron tenían un bagaje cultural inmenso. Todos los emigrantes de la primera oleada, que pertenecieron al mundo cultural, formaron parte de la nueva corriente cultural llamada Russkoe Zarubezie (Rusia en el extranjero). Estos intelectuales y artistas, portadores de la cultura rusa, expresaron, a través de sus obras, su descontento y rechazo contra la política, la cultura y el arte soviético.

\section{REFERENCIAS}

\section{Depósitos documentales}

Archivo General de la Federación Rusa. http://www.staterchiv.ru

Beloe Delo. Documentos sobre los militares del ex ejército zarista. http:// www.beloedelo.ru

Krasnil ArJiv. Documentos sobre la Revolución Bolchevique y Guerra Civil rusa. http://www.crasniiarjiv.ru

\section{Referencias bibliográficas}

Bocharova, Zinaida Semionovna, 2003, Rossiiskoe zarubezie (1920-1930), kak fenomen otechestvennoi istorii. Minsk, Svet.

Domnin, Ivan Vasilievich, 2006, Tvorcheskaia misli v isgnanii. Moscú, Zoria.

Egorova, Nadezda Andreevna, 2005, Russkaia emigrazia v Kitae. Cheliabinsk, SVT.

Figes, Orlando, 2000, La Revolución Rusa, 1891-1924. La tragedia de un pueblo. Barcelona, Edhasa.

Fiodorova, Valeria Ivanovna, 1990, Beloe dvizenie (Movimiento Blanco). Moscú, Luch.

GlavaSKII, Mijail Evgenich, 2000, Filosofskii korabil 1922. San Petersburgo, Zoria.

GoldIN, Vasilii Ivanovich, 2001, Voennii mir russkogo zarubezia: lindi y sudbi. Moscú, Luch.

GuSEVA, Katerina, 2009, Russkaia emigrazia vo Franzii: sozialnaia historia: lindi y sudbi. Moscú, Luch.

JMirov, Dmitrii Vladimirovich, 2011, Russkaia Pravoslavnaia Zercov za granizei (1920-1945) v otechestvennoi y zarubeznoi istoriografii. San Peterburg, Svet.

IofFe, Genadii, 2005, Fevralskaia revoliuzia 1917. Sug, Petersburgo. 
KARPENKO, Sergei Vladimirovich, 2009, Ocherki istorii belogo dvizenia na inge Rosii (1917-1920). Rostov, Zoria.

KISELEV, Alexei Fiedorovich, 2011, Politicheskia historia russkoi emigrazii. Minsk, SRL.

KosTiKov, Valeri Victorovich, 2005, V izgnanii: puti y sudbi russkoi emigrazii. Moscú, Luch.

Kovalev, Vladimir Victorovich, 2003, Povsednevnaia zizni vo franzuskoi emigrazii y adaptazia 1917-1930. San Petersburgo, Zoria.

Kvakin, Andrei Borisovich, 2000, Reflexión o filosofskom parajode. Moscú, Svet.

Macarov, Vladimir Genadievich y Valentin Sergeevich Cristoforov, 2004, Pasaziri russkogo parajoda (sudbi russkoi emigrazii). Moscú, Luch.

Melijos, Genadii Vasilievich, 2004, Russkaia emigrazia v Kitae v 1917-1924. San Petersburgo, Zoria.

OrLOv, Mijail Borisovich, 2006, Oktiabrskaia revolinzia y istorichceskaia nanki. Minsk, SLK.

Pavlov, Piotr, 2005, «Kto y kogda pokinul Rossiui v ZZ veke». Demoscop Weekly, 251.

Pronin, Alexei Ivanovich, 2009, Russkaia emigrazia kak obiekt issledovania. Moscú, Svet.

Protasova, Elena Igorovna, 2005, Russkaia emigrazia v Checoslovakii 19201930. Arjangelsk, ARS.

SEMENOv, Konstantin Konstantinovich, 2010, Russakia voennaia emigraziavo Franzii v 1920-1945. Arjangelsk, ARS.

SemochkinA, Evgenia Ivanovna, 2009, Historia russkoi emigrazii. xx vek. San Petersburgo, Zoria.

Skarenko, Albina, Kirilovna, 2003, Belaia Emigrazia. Moscú, Luch.

Slobodin, Vladimir Pavlovich, 2001, Beloedvizenie v Rossii (1917-1922). Arjangelsk, ARS.

SOlNZEVA-NAKOVA, Evgenia, 2011, Russkoe zarubezie y slavianskii mir. Moscú, SRL.

TARAsiev, Alexei, 2000, Russkie dujovniki v Servii (1917-1940). Moscú, Svet.

TribunskiY, Pavel Alexeevich, Sergei Vladimirovich ZuRAVlev y Lev Ivanovich GuSMAN, 2011, Russkoe nauchnoe zarubezie: liudi, trudi, instituzii, arjiva. Arjangelsk, Zoria.

URIADOvA, Anna Ivanovna, 2005, Velikaia voina y russkaia emigraziya. Moscú, SLK.

VAVILOVA, Alexandra Ivanovna, 2006, Rossiiskoe uchenie y inzineri v emigrazii. Moscú, Luch.

Volkov, Vladimir, 2003, Risskoe voisko zagranizei: epopeya v Galípoli. Moscu, Universidad Estatal de Moscú. 
Volkov, Vladimir, 2004, Tragedia russkij ofizerov: ofizerskii corpus $v$ Rossii vo vremia revoliuzii. Moscú, Universidad Estatal de Moscú.

ZEPILOVA, Valentina Ivanovna, 2000, Istoricheskaia nauka Russkogo zarubezia v 1920-80. Ecaterinburgo.

Zhukovskaia, Daria, 2004, «Prichini y sudbi russkoi emigrazii posle Revoliutzii 1917 goda», Historicus, 36 (2004): 23. 